\title{
What a Parrot's Mind Adds to Play: The Urge to Produce Novelty Fosters Tool Use Acquisition in Kea
}

\author{
Gyula K. Gajdon ${ }^{1 *}$, Melanie Lichtnegger², Ludwig Huber ${ }^{1,2}$ \\ ${ }^{1}$ Messerli Research Institute, University of Veterinary Medicine Vienna, Vienna, Austria \\ ${ }^{2}$ Department of Cognitive Biology, University of Vienna, Vienna, Austria \\ Email: "gyula.gajdon@vetmeduni.ac.at
}

Received 28 January 2014; revised 5 March 2014; accepted 14 March 2014

Copyright (C) 2014 by authors and Scientific Research Publishing Inc.

This work is licensed under the Creative Commons Attribution International License (CC BY). http://creativecommons.org/licenses/by/4.0/

(c) (i) Open Access

\begin{abstract}
Motivational and cognitive aspects of spontaneous tool-use acquisition in species that do not do so habitually, remain an open but most relevant question. To address this, we studied captive kea (Nestor notabilis), New Zealand mountain parrots renowned for their playful cleverness. The majority of adolescent, but not the adult kea, showed a toddler-like motivation to insert objects into empty tubes and also spontaneously used objects in order to eject food from inside a tube. This parallel what is known from object exploration in large brained mammals and shows for the first time in a habitually non-tool using bird that such a technical innovation is based on object-combining acquired outside the foraging context.
\end{abstract}

\section{Keywords}

Animal Cognition; Tool-Use Behaviour; Object Play; Object Exploration; Animal Innovation

\section{Introduction}

The hypothesis that cognition co-evolved with habitual tool-use in large-brained animals [1] is challenged by recent findings. For instance, captive rooks which are not habitual tool users in the wild, modified tools [2] in a way paralleling what a member of the habitually tool using New Caledonian crow did [3]. This indicates that domain general intelligence in larger brained birds seems to relate considerably well with physical aspects of tool use [2].

One counter-argument is the weak evidence from the field for such abilities in species that do not use tools

${ }^{*}$ Corresponding author. 
habitually [4]. Reports on the initial acquisition of producing a spatial relation between the tool and the target item that is out of direct reach remains anecdotal at best, even for those species in captivity [5] or subjects were reinforced to do so from the beginning [6]. Therefore, the initial mechanisms of spontaneous tool-use acquisition in such species remain an open but most relevant question. The kea is particularly interesting regarding this question because parrots in general are large brained, kea are renowned for their problem solving abilities [7] but are not habitual tool user, and in contrast to corvids (on which most tool-use studies were conducted in birds) kea and most parrots neither construct nests with twigs, nor do they cache food (putting food items into holes and covering them). Thus, kea lack such predispositions to produce spatial relations between objects both of which are discussed as being relevant to facilitate tool-use acquisition [8]. Nevertheless, some of our captive kea even discovered how to use rods instead of blocks to access food once they had achieved the skill described here [9] (see [10] for Goffin's cockatoo).

In contrast to our previous studies, the present paper focuses not on the cognitive mechanisms once tool use is acquired in a species that naturally does not do so. Rather we provide unique data on how this phenomenon was initially achieved. For this purpose we intensively scanned our group for birds that would insert toddler toys into empty tubes two metres nearby (Tube/toy Test) and what the possible intention of such object combining was by testing individually separated birds, whom were offered open and closed tubes (Intention Task). Thereafter we presented the first task where subjects had to release food from inside a tube by inserting a wooden block into it (Means-end Task). The sight of reward might distract especially younger birds to establish spatial relations between the reward and other objects, while it may trigger older birds to show a bigger behavioural repertoire including object combinations than when there is no reward. However, our hypothesis was that the individuals that display a greater behavioural repertoire that includes object inserting in not rewarded settings, will be more likely to find this solution in the Means-end Task as well [11].

\section{Methods}

\subsection{Subjects and Housing Conditions}

Twelve kea were housed in a $600 \mathrm{~m}^{3}$ outdoor aviary at the Konrad Lorenz Institute for Ethology, Vienna (Table 1). All kea beside the oldest male had participated in earlier experiments, some of which required the adult and subadult birds to remove food from transparent tubes. However, the kea had never been required to insert objects. All birds with the exception of captive reared adult male Mismo were hatched at the institute. Two adult birds (the oldest male and a breeding female) were not motivated to take part in individual tests.

Kea were fed twice a day. The aviary was furnished with perches, wooden shelters and a water pond. The ground was covered with sand where there was also access to gravel, stones, wooden pieces and dead leaves. Guidelines for environmental enrichment in the kea lab allowed offering novel objects that the birds can destroy and, optionally, extract food from (similar to the foraging of wild kea), with the restriction that kea may not be exposed to enrichment that provided experience for complex manipulation. Environmental enrichment was approved by the head of the kea lab (GG) in the weekly lab meetings, and any resulting arrangements were documented in the lab journal.

\subsection{Apparatuses}

Grey opaque PVC-tubes with an inner diameter of $48 \mathrm{~mm}$ were used in this study. They were fixed vertically with the upper edge of the tubes $10 \mathrm{~cm}$ above the ground in the Tube/toy Test and the Intention Task. In the Tube/toy Test, three tubes, each, were installed in the three $5 \times 10 \mathrm{~m}$ big compartments of the aviary (with 60 $\mathrm{cm}$ distance between the tubes in a patch). In the Intention Task, five pairs of tubes were offered in the test compartment (with $1 \mathrm{~m}$ distance between tubes of a pair), and the top of one tube in each pair was closed with a wooden disc (Figure 1(a)).

In the Means-end Task, two $20 \mathrm{~cm}$ long tubes were mounted in a slanted position above the ground as depicted in Figure 2(c), so that the middle of the upper opening was $18 \mathrm{~cm}$ above the ground, slightly below the bill of a standing kea. The top end of one tube was blocked by wire mesh (Figures 2(a) and (c)). A peanut in its shell was loosely fixed with cream cheese out of direct reach in the middle of each tube (Figures 2(a) and (b)). The peanut in the open tube could be retrieved by inserting a small block (Figure 2(c)) into the top opening of the tube so that the block would roll down the tube and knock the peanut out off its position. The nut can then be accessed at the bottom end of the tube. 
Table 1. Yes/no plot for individual kea in which session they inserted at least one experimental object into a tube in the different tasks. Tube/toy Test: number of sessions an object was inserted into a tube (out of the number of sessions the subject participated in).

\begin{tabular}{|c|c|c|c|c|c|c|c|c|c|c|c|c|}
\hline \multirow[t]{3}{*}{ Age class } & \multirow[t]{2}{*}{ Individual } & \multicolumn{11}{|l|}{ Task } \\
\hline & & \multicolumn{2}{|c|}{ Tube/toy } & \multicolumn{2}{|c|}{ Intention } & \multicolumn{3}{|c|}{ Means-end } & \multirow[b]{2}{*}{4} & \multirow[b]{2}{*}{5} & \multirow[b]{2}{*}{6} & \multirow[b]{2}{*}{7} \\
\hline & Session & & & 1 & 2 & 1 & 2 & 3 & & & & \\
\hline \multirow[t]{2}{*}{ Subadult } & Bruce (pr m) & Yes & $1(21)$ & Yes & Yes & Yes & & & & & & \\
\hline & Luke (pr m) & Yes & $5(21)$ & Yes & Yes & no & no & Yes & & & & \\
\hline \multirow[t]{5}{*}{ Juvenile } & Frowin (pr m) & Yes & $3(21)$ & Yes & Yes & Yes & & & & & & \\
\hline & Pick (hr m) & Yes & $4(21)$ & no & Yes & Yes & & & & & & \\
\hline & Zappel (hr m) & Yes & $6(21)$ & no & Yes & no & Yes & & & & & \\
\hline & Kermit (hr m) & Yes & $7(21)$ & Yes & no & no & no & Yes & & & & \\
\hline & Linus (hr m) & Yes & $3(21)$ & no & no & no & no & no & no & no & no & $\mathrm{D} /$ Yes \\
\hline \multirow[t]{5}{*}{ Adult } & John (pr m) & no & $0(21)$ & no & no & no & no & no & no & D/no & $\mathrm{D} /$ Yes & \\
\hline & Knut (pr m) & no & $0(21)$ & no & no & no & no & D/no & $\mathrm{D} /$ Yes & & & \\
\hline & Mismo (pr m) & Yes & $1(6)$ & no & no & no & Yes & & & & & \\
\hline & Kima (pr f) & no & $0(21)$ & & & & & & & & & \\
\hline & Sepperl (pr m) & no & $0(21)$ & & & & & & & & & \\
\hline
\end{tabular}

hr: hand reared; pr: parent reared; m: male; f: female; D: session with demonstration.

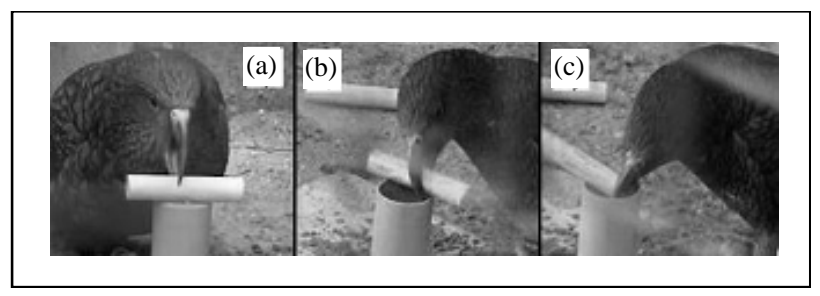

Figure 1. Parts of loose cylinders the birds combined with closed (a) and open tubes (b, c) in the Intention Task. The middle part is combined in (a) and (b), and the end in (c).

In the Tube/toy Test, a pile of twenty solid objects was offered two meters away from each patch of tubes. Objects were commercial, coloured wooden toddler blocks that differed in form and ranged from one and a half to ten centimetres in size. In the Intention Task, $10 \mathrm{~cm}$ long cylinders (Figure 1) were put between pairs of tubes. Cylinders of the Intention Task were painted light-blue, a colour not associated with the toys used so before. In the Means-end Task, pairs of octagonal wooden blocks of two sizes (2.5 cm and $10 \mathrm{~cm}$ in diameter, Figure 2(c)) were offered in front of each tube and in between the two tubes. The birds were unfamiliar with blocks of this shape.

\subsection{Procedure and Data Collection}

Tube/toy Tests were conducted with the whole group staying together. All occurrences of toy/tube combinations were recorded on a Dictaphone during 30 minutes, each, on 21 days. Toys were rearranged at the end of each session into the former three piles. Tests of the Intention and Means-end Task were run with individual birds visually separated from group members (opaque sliding doors of the test compartment of the aviary were closed). Each trial lasted a maximum of 10 minutes and was video recorded. Subjects were tested no more than once a 


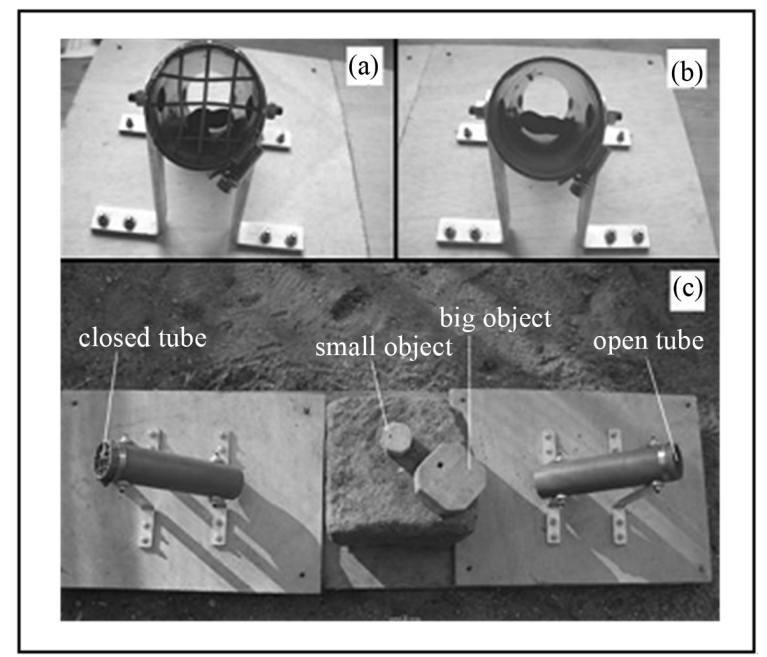

Figure 2. Apparatus of Means-end Task (c) with peanuts in closed (a) and open tube (b).

day. If the birds succeeded in retrieving the reward in the Means-end Task, they were given four additional trials in the same session. The tubes were re-baited out of sight of the birds and the apparatus was rotated randomly before each trial and its position was changed so that the apparatus did not stay in exactly the same position in all trials of a session. This was done in order to prevent recency effects of rewarded sites from the last trial.

The Tube/toy Tests were conducted first. Thereafter, birds were given one session of Intention task first, and the first four sessions altered between Intention and Means-end Task. Two subjects that had inserted cylinders in the Intention Task failed to do so in the Means-end Task although they did considerably more object combinations there (23 each) than the other three individuals whom had failed (five on average). Thus, these two subjects were given one additional session during which they solved the Means-end Task. The three remaining failing subjects were given three demonstration trials by adult Mismo then (see Table 1). Mismo demonstrated three trials half a meter behind a wire mesh sliding door in the test compartment and right before observers were tested. If an observer failed, demonstration was repeated in the beginning of the next session. At first, only kea Knut was given demonstration until he succeeded in the Means-end Task, while the others were continuously being tested without a demonstration. This procedure was repeated with John after Knut, and with Linus after John had succeeded, respectively (Table 1).

\subsection{Data Analysis}

In the Means-end Task, the number of actions directed to the apparatus was recorded from the video tapes. Type of behaviour was only relevant in terms of which object was combined where. Besides that, an action was simply defined as engaging in the same behaviour at the same object, a change in either of the two rendered the next action. All videos were analysed by GG. Intra-observer reliability for number of actions was $93 \%$, and $100 \%$ for types of object combinations.

Due to technical problems in six of the fifty trials of the Means-end task, video recordings had stopped a few seconds after start of a trial. Friedman tests handle such tables with unbalanced missing data in an unsatisfying way. Thus, a permutation analogue of the Friedman test was run in which the sum of the ranked trials was compared with those of 1000 tables randomly generated in Excel with the same missing trials. Tied ranks in the raw table were randomly reassigned for each of the thousand comparisons. $P$-values correspond to the proportion of tables with the trial's rank sums being smaller than the one of the raw table. The last three blocks of 100 tables did not change the $P$-values on its second decimal place anymore.

A permutation test was run also in order to simulate whether the subjects did the successful object combination earlier than expected by chance in the Means-end Task. Because the kea combined the blocks with each another (15 possibilities to combine two of the six objects) as well as with all parts of the tubes (top, middle and bottom part of two tubes with 6 blocks yields 36 combination possibilities), and other loose objects such as small gravel (subsumed as one object) of the compartment with the tubes (with six location options yields six 
combination possibilities), we assumed for the simulation until first success (trial 1) that there are 57 combination options, three of which will successfully release the reward (putting either of the three small blocks into the top of the open tube). Because keas like to repeat the same object combination, no measures were taken to prevent repetition of a particular combination in the simulation. It was just run in analogue of repeatedly rolling a dice with 57 sides, three of which terminate the trial. The number of throws in a simulated trial was summed up for as many simulation individuals as there was real data available for the trials/individual combinations. Two thousand such runs were calculated for each trial. Default frequencies for the simulation of replication trials 2 - 5 was according to the one shown by the birds in trial 1 . The proportion of runs with smaller or equal total number of "dice rolling" than the number of object combinations done by the kea until they had released the reward was considered as an analogue of the $P$-value. Similarly, the proportions with which the other object combinations occurred during the simulation were compared with those performed by the kea. The last three blocks of 100 runs did not change the $P$-values on its second decimal place anymore.

\section{Results}

All adolescent kea spontaneously inserted objects in the Tube/toy Test (Table 1). Some of them carried a toy straight to the closest patch of tubes and inserted it there in the first session. Only one adult kea inserted objects (twice in one session). Adolescent kea inserted objects in 4.14 sessions on average. They also dipped a toy into the opening of a tube, but did not release it (one session on average) or they put a toy on top of a tube but the toy was inappropriately oriented or too big to insert (2.75 sessions on average).

In the Intention Task, individual kea combined cylinders on average ten times more often with the open (mean 25.8 times, SE 38.9) than with the closed tubes (mean 2.5 times, SE 2.7; Wilcoxon test: $\mathrm{n}=8$; $\mathrm{Z}=-2.547$, $P=0.011$ ), and the proportion of putting the ends of the cylinders on top of open tubes (Figure 1(c), mean proportion per subject $=0.43$, SE 0.14 ), rather than the middle of the cylinder which would impede insertion (Figure 1(b)), was five times greater than that of closed tubes (0.08, SE 0.12; Wilcoxon test: $\mathrm{n}=6, \mathrm{Z}=-2.201, P=$ 0.028). When they inserted a cylinder during a session, this happened a mean of 10.4 times (SE 13.3).

In the Means-end Task, seven of the ten tested kea retrieved the peanut (Table 1). All individuals that spontaneously succeeded had also inserted objects in the non-rewarded tasks before and two of the three individuals that failed, had also failed in the non-rewarded tasks. There is a significant correlation between success and failure in rewarded and non-rewarded tasks (fourfold table coefficient, $\chi^{2}=5.833, \mathrm{df}=1 ; P<0.05$ ).

The three kea that failed to retrieve the food on their own succeeded after being given demonstrations by adult kea Mismo (see Table 1). In fact, the first object combination shown by all three observers after demonstration was the appropriate one for food retrieving (see Table 2 for a detailed description). The likelihood that all three kea that received demonstration, had succeed by chance in a demonstration session is 0.024 . (The chance that fewer individuals succeeded then, or in another session, or not at all is 0.976 , with p that inserting will happen in a session equals 1 divided by n sessions in which an individual was tested; and with p' that inserting will not happen in a session equals 1 minus p.)

Once kea had solved the Means-end Task, they required fewer actions to do so: mean number of actions per subject till first success: 167.8, SE 133.8; trial 2: 11.0, SE 7.4; trial 3: 20.0, SE 24.4; trial 4: 23.1 SE 25.4; trial 5: 15.77, SE 21.8. The permutation analogue of the Friedman test yielded that trial 1 (all $P \leq 0.002$ ), but also trial 2 (all $P \leq 0.035$ ) were significantly different ranked than the other trials.

The kea combined objects an average of 14.2 times until first success in the Means-end Task. This number does not deviate from a computer simulation that combined experimental objects by chance (Table 3). However, this result is not due to random object combinations in kea. Rather, until first success, they preferred to combine the inappropriately sized objects with the open tube and the fitting blocks with the tube end that was closed with the wire mesh (Table 3). Kea focused to combine the functionally sized object most right after first success (average number of object combinations in trials 2-5: 3.8, 5.4, 9.4, 5.0; the permutation analogue of the Friedman test yielded a significant difference between trial 1 and $2(P=0.05)$ and tendencies towards differences between trial 1 and trial 3 to $5(0.063 \leq$ all $P \leq 0.082)$.

\section{Discussion}

Our results demonstrate the presence of an astonishing intrinsic motivation in a naturally non-tool using bird species to combine objects. Despite their lack of a disposition to combine objects in other contexts such as food- 
Table 2. Description of inserting as means in observers.

Adult male John:

Kea John did not combine objects in the 212 actions he directed at the apparatus in the four sessions before he was given a demonstration. In the first session after the demonstration, he was highly active and performed 212 actions (mainly rummaging sand from the edge of the apparatus in 53 actions and rummaging big blocks in 99 actions), but he didn't combine any objects. In the second session after observing a demonstrator, his 58th action was the first and correct object combination to retrieve the food. His object manipulation had some playful connotation, e.g. shortly before inserting the small block, he tossed the block into the air.

Adult male Knut:

Knut combined objects six times during the 64 actions he performed in the two sessions before being given a demonstration. Three times he combined a small block with a big one, once he put a big block on the middle part of the open tube and twice he put a small block to the lower end of the closed tube but did not insert it into the tube. In the first session after the demonstration, Knut performed 42 actions. Thus, he seemed not to be as activated as John was. But like John, he didn't combine any objects in this session. In the second demonstration session, his 9th action was the first and correct object combination to retrieve the food.

Juvenile male Linus:

Linus combined objects nine times during the 228 actions he performed in the six sessions before demonstration. But all nine object combinations were done during the first two sessions: four times, he put the small block on the top end and once on the middle part of the closed tube, and one time each, he put the big block on the top and the lower end of both tubes. During the 133 actions of sessions 3 to 6, he didn't combine objects anymore. In the first session after demonstration, he combined the small block with the top end of the open tube in his second action of the session (after looking into the tube). But he released it too early in order to insert it properly into the tube. He held the block to the edge of the opening once again, hesitated, and carried the block to the closed tube. There, he combined it with the top end and on the middle part of the tube for a total of 9 times, before he did so twice on the middle part of the open tube and then inserted it into the top end there, releasing the reward as the 14th object combination out of a total of 48 actions in this session. Prior to success within this session he had combined the block with the apparatus several times in a manner of tossing it down on the apparatus.

caching or constructing nests, kea spontaneously inserted objects into tubes during many test sessions before the tubes were rewarded with food (Table 1). The subjects that engaged in object inserting already in the non-rewarded tasks predominantly succeeded on their own to retrieve the reward in the Means-end Task. This demonstrated that the latter success is based on achievements acquired outside the foraging context. Since such inserting behaviour was almost exclusively performed by adolescent kea, it is likely that the behaviour was driven by a toddler-like playful motivation to explore the characteristics of spatial relations that can be produced between objects [12]. Establishing spatial relations between objects has been considered a precursor of tool-use behaviour in mammals [13] [14] and its explorative nature has been stressed for tool-use acquisition in children [15].

It is of special interest that the kea were in particular interested in combining inappropriately sized objects with the tubes in the Means-end Task before first success and that they maintained some explorative object combining. This considerably contrasts the results of Bird \& Emery [2] in regard to the rooks that always chose the functional stone from a new pair in the rewarded tube task. Experience is fundamental for cognition, and exploring the variation of behavioural schemata and its outcome can be important for learning the invariants of a task [12] [15]. Therefore, besides considering whether animals react immediately in the most efficient manner in specific settings, the evaluation of a species' intelligence should include in which way subjects actively gather information that will lead them to further achievements on their own.

The performance of kea is intelligent in this respect because it results from active information acquisition including advanced cognition: previous experience and current information are flexibly combined in a way to probe the production of new relations between objects. We think that rather than motivation to explore objects [4] [8] or cognitive potential alone, it is the assembly of both of them that scaffolded initial tool use in kea. The basic link between explorative object combining and cognition is also indicated by Irene Pepperberg's languagetrained grey parrot Griffin that started to combine unrewarded objects when he started to combine words [16].

Such an explorative intelligence may be present in many large-brained species [17], and especially during adolescence. It renders a completely different character to its innovative capacity from the one indicated in Epstein's study where pigeons "automatically" chained all separately trained parts of tool-use behaviour to a functional whole [18]: the kea achieved the basic skill of inserting with no food reward at all and despite the lack of precursor behaviour for food caching or constructing nest cubs that are proposed to scaffold tool-use in corvids 
Table 3. Frequency of object combinations in the Means-end Task as performed by the kea and frequencies that resulted from a simulation (see Methods). Mean number of times the subjects combined objects (top line) and relative frequencies of different object combinations until retrieving the reward by inserting the small block into the top of the open tube in the different trials. Second line of indicated object combination gives the values of the simulation $( \pm \mathrm{SE})$; see legend.

\begin{tabular}{|c|c|c|c|c|c|c|c|}
\hline & & & a & $\mathrm{b}$ & $\mathrm{b}$ & $\mathrm{b}$ & $\mathrm{b}$ \\
\hline Tube & Object & Part of tube & Trial $1(\mathrm{~N}=10)$ & Trial $2(\mathrm{~N}=8)$ & Trial $3(\mathrm{~N}=8)$ & Trial $4(\mathrm{~N}=9)$ & Trial $5(\mathrm{~N}=9)$ \\
\hline \multirow[t]{9}{*}{ Open } & Small block & Top end & $\begin{array}{c}14.20 \\
18.95 \pm 5.74\end{array}$ & $\begin{array}{c}3.75^{*} \\
10.88 \pm 3.69\end{array}$ & $\begin{array}{c}5.38^{*} \\
10.79 \pm 3.68\end{array}$ & $\begin{array}{c}9.33 \\
10.98 \pm 3.50\end{array}$ & $\begin{array}{c}5.00^{*} \\
10.82 \pm 3.41\end{array}$ \\
\hline & \multirow{5}{*}{ Big block } & Middle & $\begin{array}{c}0.01^{\dagger} \\
0.05 \pm 0.02\end{array}$ & $\begin{array}{c}0 \\
0.01 \pm 0.01\end{array}$ & $\begin{array}{c}0 \\
0.01 \pm 0.01\end{array}$ & $\begin{array}{c}0.01 \\
0.01 \pm 0.01\end{array}$ & $\begin{array}{c}0 \\
0.01 \pm 0.01\end{array}$ \\
\hline & & Lower end & $\begin{array}{c}0.01^{\dagger} \\
0.05 \pm 0.02\end{array}$ & $\begin{array}{c}0.27^{*} \\
0.01 \pm 0.01\end{array}$ & $\begin{array}{c}0.05^{*} \\
0.01 \pm 0.01\end{array}$ & $\begin{array}{c}0.11^{*} \\
0.01 \pm 0.01\end{array}$ & $\begin{array}{c}0.18^{*} \\
0.01 \pm 0.01\end{array}$ \\
\hline & & Top end & $\begin{array}{c}0.13^{*} \\
0.05 \pm 0.02\end{array}$ & $\begin{array}{c}0.03^{\dagger} \\
0.13 \pm 0.04\end{array}$ & $\begin{array}{c}0.05^{\dagger} \\
0.13 \pm 0.04\end{array}$ & $\begin{array}{c}0.06^{\dagger} \\
0.13 \pm 0.04\end{array}$ & $\begin{array}{c}0.04^{\dagger} \\
0.13 \pm 0.04\end{array}$ \\
\hline & & Middle & $\begin{array}{c}0.11^{*} \\
0.05 \pm 0.02\end{array}$ & $\begin{array}{c}0^{\dagger} \\
0.11 \pm 0.03\end{array}$ & $\begin{array}{c}0.07 \\
0.11 \pm 0.03\end{array}$ & $\begin{array}{c}0.02^{\dagger} \\
0.11 \pm 0.03\end{array}$ & $\begin{array}{c}0.09 \\
0.11 \pm 0.03\end{array}$ \\
\hline & & Lower end & $\begin{array}{c}0.01^{\dagger} \\
0.05 \pm 0.02\end{array}$ & $\begin{array}{c}0 \\
0.01 \pm 0.01\end{array}$ & $\begin{array}{c}0 \\
0.01 \pm 0.01\end{array}$ & $\begin{array}{c}0.05^{*} \\
0.01 \pm 0.01\end{array}$ & $\begin{array}{c}0.02^{*} \mathrm{t} \\
0.01 \pm 0.01\end{array}$ \\
\hline & \multirow[t]{3}{*}{ Other object } & Top end & $\begin{array}{c}0.10^{*} \\
0.02 \pm 0.01\end{array}$ & $\begin{array}{c}0^{\dagger} \\
0.10 \pm 0.03\end{array}$ & $\begin{array}{c}0^{\dagger} \\
0.10 \pm 0.03\end{array}$ & $\begin{array}{c}0.01^{\dagger} \\
0.10 \pm 0.03\end{array}$ & $\begin{array}{c}0^{\dagger} \\
0.10 \pm 0.03\end{array}$ \\
\hline & & Middle & $\begin{array}{c}0^{\dagger} \mathrm{t} \\
0.02 \pm 0.01\end{array}$ & $\begin{array}{l}0 \\
-\end{array}$ & $\begin{array}{c}0.09 \\
-\end{array}$ & $\begin{array}{l}0 \\
-\end{array}$ & $\begin{array}{l}0 \\
-\end{array}$ \\
\hline & & Lower end & $\begin{array}{c}0^{\dagger} \mathrm{t} \\
0.02 \pm 0.01\end{array}$ & $\begin{array}{l}0 \\
-\end{array}$ & $\begin{array}{l}0 \\
-\end{array}$ & $\begin{array}{l}0 \\
-\end{array}$ & $\begin{array}{l}0 \\
-\end{array}$ \\
\hline \multirow[t]{9}{*}{ Closed } & \multirow[t]{3}{*}{ Small block } & Top end & $\begin{array}{c}0.15^{*} \\
0.05 \pm 0.02\end{array}$ & $\begin{array}{c}0.23^{*} \\
0.15 \pm 0.04\end{array}$ & $\begin{array}{c}0.26^{*} \\
0.14 \pm 0.04\end{array}$ & $\begin{array}{c}0.23^{*} \\
0.15 \pm 0.04\end{array}$ & $\begin{array}{c}0.22^{*} \\
0.15 \pm 0.04\end{array}$ \\
\hline & & Middle & $\begin{array}{c}0.04 \\
0.05 \pm 0.02\end{array}$ & $\begin{array}{c}0^{\dagger} \mathrm{t} \\
0.04 \pm 0.02\end{array}$ & $\begin{array}{c}0.02 \\
0.04 \pm 0.02\end{array}$ & $\begin{array}{c}0^{\dagger} \\
0.04 \pm 0.02\end{array}$ & $\begin{array}{c}0^{\dagger} \\
0.04 \pm 0.02\end{array}$ \\
\hline & & Lower end & $\begin{array}{c}0.12^{*} \\
0.05 \pm 0.02\end{array}$ & $\begin{array}{c}0.10 \\
0.12 \pm 0.04\end{array}$ & $\begin{array}{c}0.09 \\
0.12 \pm 0.04\end{array}$ & $\begin{array}{c}0.07^{\dagger} \mathrm{t} \\
0.12 \pm 0.03\end{array}$ & $\begin{array}{c}0.02^{\dagger} \\
0.12 \pm 0.03\end{array}$ \\
\hline & \multirow[t]{3}{*}{ Big block } & Top end & $\begin{array}{c}0.06 \\
0.05 \pm 0.02\end{array}$ & $\begin{array}{c}0.03 \\
0.06 \pm 0.03\end{array}$ & $\begin{array}{c}0.12^{*} \\
0.06 \pm 0.03\end{array}$ & $\begin{array}{c}0.04 \\
0.06 \pm 0.02\end{array}$ & $\begin{array}{c}0.09^{*} \mathrm{t} \\
0.05 \pm 0.02\end{array}$ \\
\hline & & Middle & $\begin{array}{c}0.03^{\dagger} \mathrm{t} \\
0.05 \pm 0.02\end{array}$ & $\begin{array}{c}0 \\
0.03 \pm 0.02\end{array}$ & $\begin{array}{c}0.07^{*} \\
0.03 \pm 0.02\end{array}$ & $\begin{array}{c}0.02 \\
0.03 \pm 0.02\end{array}$ & $\begin{array}{c}0.04 \\
0.03 \pm 0.02\end{array}$ \\
\hline & & Lower end & $\begin{array}{c}0.01^{\dagger} \\
0.05 \pm 0.02\end{array}$ & $\begin{array}{c}0 \\
0.01 \pm 0.01\end{array}$ & $\begin{array}{c}0 \\
0.01 \pm 0.01\end{array}$ & $\begin{array}{c}0.02 \\
0.01 \pm 0.01\end{array}$ & $\begin{array}{c}0.04^{*} \\
0.01 \pm 0.01\end{array}$ \\
\hline & \multirow[t]{3}{*}{ Other object } & Top end & $\begin{array}{c}0^{\dagger} \mathrm{t} \\
0.02 \pm 0.01\end{array}$ & $\begin{array}{l}0 \\
-\end{array}$ & $\begin{array}{l}0 \\
-\end{array}$ & $\begin{array}{c}0.23 \\
-\end{array}$ & $\begin{array}{l}0 \\
-\end{array}$ \\
\hline & & Middle & $\begin{array}{c}0^{\dagger} \mathrm{t} \\
0.02 \pm 0.01\end{array}$ & $\begin{array}{l}0 \\
-\end{array}$ & $\begin{array}{l}0 \\
-\end{array}$ & $\begin{array}{l}0 \\
-\end{array}$ & $\begin{array}{l}0 \\
-\end{array}$ \\
\hline & & Lower end & $\begin{array}{c}0^{\dagger} \\
0.02 \pm 0.01\end{array}$ & $\begin{array}{l}0 \\
-\end{array}$ & $\begin{array}{l}0 \\
-\end{array}$ & $\begin{array}{l}0 \\
-\end{array}$ & $\begin{array}{l}0 \\
-\end{array}$ \\
\hline - & $\begin{array}{l}\text { Either two } \\
\text { blocks }\end{array}$ & - & $\begin{array}{c}0.13^{\dagger} \\
0.26 \pm 0.04\end{array}$ & $\begin{array}{c}0^{\dagger} \\
0.13 \pm 0.04\end{array}$ & $\begin{array}{c}0^{\dagger} \\
0.13 \pm 0.04\end{array}$ & $\begin{array}{c}0.01^{\dagger} \\
0.13 \pm 0.04\end{array}$ & $\begin{array}{c}0^{\dagger} \\
0.13 \pm 0.03\end{array}$ \\
\hline
\end{tabular}

a: default frequencies for the simulation according to a 57 combination schedule (see methods); b: default frequency for the simulation according to the one shown by the birds in trial $1 .{ }^{*}$ Value significantly $(P \leq 0.05)$ bigger than; or ${ }^{\dagger}$ smaller than the one expected according to the simulation. t: tendency of difference $(P \leq 0.1)$

[8]. This shows a similarity in object exploration between large brained mammals and birds and contributes to the recently increasing body of evidence that they demonstrate a similar cognitive potential [19] [20].

\section{Acknowledgements}

This research was financed by the Austrian Science Foundation FWF, Project No. P19087-B17. Testing was discussed and approved by the institutional ethics committee in accordance with Good Scientific Practice guide- 
lines and national legislations.

\section{References}

[1] van Schaik, C.P., Daener, R.O. and Merrill, M.Y. (1999) The Conditions for Tool Use in Primates: Implications for the Evolution of Material Culture. Journal of Human Evolution, 36, 719-741. http://dx.doi.org/10.1006/jhev.1999.0304

[2] Bird, C.D. and Emery, N.J. (2009) Insightful Problem Solving and Creative Tool Modification by Captive NontoolUsing Rooks. PNAS, 106, 10370-10375. http://dx.doi.org/10.1073/pnas.0901008106

[3] Weir, A.A.S., Chappel, J. and Kacelnik, A. (2002) Shaping of Hooks in New Caledonian Crow. Science, $297,981$. http://dx.doi.org/10.1126/science.1073433

[4] Kacelnik, A. (2009) Tools for Thought or Thoughts for Tools? PNAS, 106, 10071-10072. http://dx.doi.org/10.1073/pnas.0904735106

[5] Jones, T.B. and Kamil, A.C. (1973) Tool-Making and Tool-Using in the Northern Blue Jay. Science, 180, $1076-1078$. http://dx.doi.org/10.1126/science.180.4090.1076

[6] Lind, J., Ghirlanda, S. and Enquist, M. (2009) Insight Learning or Shaping? PNAS, 106, E76. http://dx.doi.org/10.1073/pnas.0906120106

[7] Huber, L. and Gajdon, G.K. (2006) Technical Intelligence in Animals: The Kea Model. Animal Cognition, 9, $295-305$. http://dx.doi.org/10.1007/s10071-006-0033-8

[8] Kenward, B., Schlögl, C., Rutz, C., Weir, A.A.S., Bugnyar, T. and Kacelnik, A. (2011) On the Evolutionary and Ontogenetic Origins of Tool-Oriented Behaviour in New Caledonian Crows (Corvus moneduloides). Biological Journal of the Linnean Society, 102, 870-877. http://dx.doi.org/10.1111/j.1095-8312.2011.01613.x

[9] Auersperg, A.M.I., von Bayern, A.M.F., Gajdon, G.K., Huber, L. and Kacelnik, A. (2011) Flexibility in Problem Solving and Tool Use of Kea and New Caledonian Crows in a Multi Access Box Paradigm. PLos ONE, 6, e20231. http://dx.doi.org/10.1371/journal.pone.0020231

[10] Auersperg, A.M.I., Szabo, B., von Bayern, A.M.P. and Kacelnik, A. (2012) Spontaneous Innovation in Tool Manufacture and Use in a Goffin's Cockatoo. Current Biology, 22, R903-R904. http://dx.doi.org/10.1016/j.cub.2012.09.002

[11] Benson-Amram, S. and Holekamp, K.E. (2012) Innovative Problem Solving by Wild Spotted Hyenas. Proceedings of the Royal Society, London B, 279, 4087-4095. http://dx.doi.org/10.1098/rspb.2012.1450

[12] Piaget, J. and Inhelder, B. (1969) The Psychology of the Child. Basic Books, New York.

[13] Torigoe, T. (1985) Comparison of Object Manipulation among 74 Species of Non-Human Primates. Primates, 26, 182194. http://dx.doi.org/10.1007/BF02382017

[14] Visalberghi, E. and Fragaszy, D.M. (2006) What Is Challenging about Tool Use? The Capuchin's Perspective. In: Wasserman, E.A. and Zentall, T.R., Eds., Comparative Cognition. Experimental Explorations of Animal Intelligence, Oxford University Press, Oxford, 529-552.

[15] Lockman, J.J. (2000) A Perception-Action Perspective on Tool Use Evelopment. Child Development, 71, $137-144$. http://dx.doi.org/10.1111/1467-8624.00127

[16] Pepperberg, I.M. and Shive, H.R. (2001) Simultanous Development of Vocal and Physical Object Combinations in a Grey Parrot (Psittacus erithacus): Bottles Caps, Lids and Labels. Journal of Comparative Psychology, 115, 376-384. http://dx.doi.org/10.1037/0735-7036.115.4.376

[17] McCowan, B., Marino, L., Vance, E., Walke, L. and Reiss, D. (2000) Bubble Ring Play of Bottlenose Dolphins (Tursiops truncatus): Implications for Cognition. Journal of Comparative Psychology, 114, 98-106. http://dx.doi.org/10.1037/0735-7036.114.1.98

[18] Epstein, R., Kirshnit, C.E., Lanza, R.P. and Rubin, L.C. (1984) “Insight” in the Pigeon: Antecedents and Determinants of an Inteligent Performance. Nature, 308, 61-62. http://dx.doi.org/10.1038/308061a0

[19] Emery, N.J. and Clayton, N.S. (2004) The Mentality of Crows: Convergent Evolution of Intelligence in Corvids and Apes. Science, 306, 1903-1907. http://dx.doi.org/10.1126/science.1098410

[20] Veit, L. and Nieder, A. (2013) Abstract Rule Neurons in the Endbrain Support Intelligent Behaviour in Corvid Songbirds. Nature Comunications, 4, Article ID: 2878. 